Revista de Economia Política, vol. 40, n 1, pp. 3-21, janeiro-março/2020

\title{
A geoeconomia do império e as mutações do capital: os dois ciclos de expansão econômica dos Estados Unidos no final do século $\mathrm{XX}^{1}$
}

\author{
The geoeconomics of the empire and the \\ mutations of the capital: the two cycles of \\ US economic expansion in the late twentieth century
}

MARIA DA CONCEIÇÃO TAVARES****

MAURICIO METRI***

\begin{abstract}
RESUMO: Este artigo, escrito em 2003-04, tem como objetivo analisar os dois ciclos de expansão econômica dos Estados Unidos no final do século XX e a crise financeira de 2001 que lhes sucedeu. Para tanto, parte-se de um exame das mutações do capital, sobretudo a partir da década de 1970. Ao final, empreende-se uma reflexão sobre a conjuntural internacional e as mudanças da natureza da hegemonia dos Estados Unidos no início do século XXI.

PALAVRAS-CHAVE: Globalização; ciclo econômico; Estados Unidos; crise financeira.
\end{abstract}

ABSTRACT: This paper was written in 2003-04 and aims to investigate the two cycles of US economic expansion in the late of the 20th Century and the 2001 financial crisis. For this purpose, it starts an examination of the mutations of the capital since the 1970s. In the end, it analyzes the international context and the changes in the US hegemony nature at the beginnings of the 21st Century.

KEYWORDS: Globalization; economic cycle; United States; financial crisis.

JEL Classification: G01; E44; F30; F5.

\footnotetext{
${ }^{1}$ Este artigo fez parte da pesquisa "Império Americano: uma economia política do poder global", elaborada pelo Grupo de Economia Política do IE/UFRJ entre 2002-2003. Um primeira versão foi entregue à FAPERJ em abril de 2003, e uma segunda, terminada em junho de 2004 seria para publicação em um livro, o que não ocorreu. Redescoberto recentemente, os autores acharam por bem mantê-lo como finalizado em 2004, sem outras revisões e atualizações. No entanto, retiraram algumas partes para que o texto se adequasse aos padrões da Revista. Preservaram, de todo modo, as reflexões como desenvolvidas há 15 anos.

* Professora emérita da Universidade Federal do Rio de Janeiro - UFRJ, do Instituto de Economia, Rio de Janeiro/RJ, Brasil. E-mail: mctavares@visualnet.com.br. Orcid: https://orcid.org/0000-0003-2214-7516.

** Professora titular aposentada do IE-Unicamp.

*** Professor associado de Economia Política Internacional do Instituto de Relações Internacionais e Defesa da UFRJ - IRI/UFRJ, Rio de Janeiro/RJ, Brasil. E-mail: metri.mauricio@gmail.com. Orcid. https://orcid.org/0000-0001-6564-2731. Submetido: 1/Abril/2019; Aprovado: 27/Agosto/2019.
} 


\section{A INTERNACIONALIZAÇÃO DO CAPITAL E A GLOBALIZAÇÃO FINANCEIRA}

Tornou-se lugar-comum em nossos dias tirar proveito da imprecisão do conceito de "globalização" para dizer-se que a tendência a uma crescente interdependência das economias do mundo não é um fenômeno novo, mas velho como o capitalismo. Este tipo de afirmação não ajuda a esclarecer fatos e mitos ligados à globalização.

A internacionalização do capital sob forma comercial e de crédito é um processo que nasceu junto com a expansão do capitalismo mercantil intraeuropeu e estendeu-se rapidamente desde o estabelecimento dos impérios coloniais do século XVI em diante. Já a internacionalização produtiva só veio a ocorrer depois da primeira revolução industrial inglesa. A primeira onda de investimento deu-se a partir da expansão das filiais inglesas no mundo, sobretudo nos setores de infraestrutura (transportes, comunicações e empresas de utilidade pública). Essa expansão acompanhou e confirmou a divisão internacional do trabalho sob a hegemonia da Inglaterra (o Centro produtor de manufaturas e a Periferia produtora de alimentos e matérias-primas). ${ }^{2}$ Como resultado dessa onda de investimento direto, o comércio mundial expandiu-se numa velocidade sem precedente, sob a égide do padrão ouro-libra, da Hegemonia Inglesa e da Pax Brittanica.

A partir de 1870 até 1914, ocorrem dois movimentos fundamentais do ponto de vista geoeconômico. Houve a liberalização dos mercados de capitais impulsionada pela City de Londres e acompanhada por Wall Street, e também o aumento da rivalidade econômica entre as grandes potências pela conquista de novos mercados. A segunda onda de internacionalização produtiva aprofundou-se, portanto, pela concorrência interestatal e por uma expansão e concentração do capital financeiro sem precedentes no sistema capitalista. ${ }^{3}$ Estendeu-se à Periferia a partir da ação das grandes potências e de suas corporações em países de vários continentes, tanto os colonizados quanto os descolonizados pelos velhos impérios europeus. A busca de matérias-primas estratégicas, ouro e reservas de minerais para metalurgia, dos ferrosos e não ferrosos, constitui-se no objetivo fundamental dessa onda de transnacionalização produtiva, à qual se sucedeu a do petróleo, já no início do Séc. XX.

A terceira onda de internacionalização produtiva aconteceu no pós-guerra, já sob a hegemonia Norte-americana. Essa onda teve como origem a reconstrução europeia e japonesa e liderada pela expansão das corporações norte-americanas. Intensificou-se depois pela concorrência entre os grandes complexos manufatureiros dos países industrializados, iniciada pela expansão das corporações de origem europeia, sobretudo as alemãs, e pela onda de investimento direto das filiais japonesas. Essa "transnacionalização" não deu lugar a uma liberalização comercial e financeira do

\footnotetext{
${ }^{2}$ Ver Prebisch (1949) e Triffin (1972).

${ }^{3}$ Ver Hobson (1983).
} 
tipo da ocorrida sob o padrão libra-ouro. Pelo contrário, no caso dos EUA, a maior expansão comercial estruturou-se entre matrizes e filiais manufatureiras que saltaram as barreiras protecionistas nacionais e regionais. Tampouco pouco houve liberalização do movimento de capitais durante a vigência do regime de Bretton Woods.

A nova globalização financeira é um fenômeno mais recente do final do Séc. XX. Só com a ruptura do padrão dólar (1971-73) começou a flutuação cambial e a desregulamentação financeira que levou ao aumento brutal e "global" dos fluxos financeiros de capitais. Desde então, a flutuação das principais moedas constitui-se ao mesmo tempo num resultado das políticas do FED, dos movimentos de capitais e um acelerador dos desequilíbrios estruturais dos balanços de pagamentos nacionais.

Cresceram prodigiosamente também os fluxos de capital financeiro desterritorializados (off-shore) denominados em dólares, promovendo uma verdadeira "dolarização" dos mercados financeiros globalizados e uma onda de inovações financeiras, que entronizaram definitivamente a moeda Norte-americana como unidade obrigatória de referência das finanças internacionais privadas para operações de securitização (hedge) e arbitragem, ligadas às flutuações dos juros e do câmbio das principais moedas.

Do ponto de vista macroeconômico, as últimas décadas do Séc. XX caracterizaram-se por uma expansão excepcional do comércio e sobretudo do capital financeiro privado. O núcleo irradiador do comércio internacional encontra-se na expansão das empresas expansão das empresas multinacionais para a Ásia e nos déficits crescentes dos EUA. Estes foram financiados pelos países superavitários, que acumularam os maiores estoques de títulos do Tesouro Norte-Americano e de divisas dolarizadas.

No caso dos países periféricos, observa-se que a participação no jogo da globalização financeira tornou-se mais complicada, uma vez que se inserem, em geral, apenas como países receptores de capitais especulativos, de padrões de consumo e "cultura" globais difundidos a partir do Centro hegemônico e como usuários de tecnologias já amortizadas, que não controlam nem produzem internamente.

As políticas neoliberais são o "espelho" da globalização financeira, e seus efeitos sobre a distribuição de renda, o mercado de trabalho e as políticas sociais para a maioria das populações do mundo tem sido francamente negativos, como reconhecem abertamente os últimos relatórios da OIT, da UNCTAD, da CEPAL e mais veladamente os do próprio Banco Mundial. As políticas de liberalização e desregulamentação financeira tendem a elevar os juros e a pressionar os orçamentos fiscais, o que acarreta impactos desastrosos sobre o crescimento, o emprego e as políticas públicas, sobretudo nas economias periféricas, além de ampliar o hiato entre ricos e pobres.

De modo mais geral, a concentração da riqueza em suas várias formas, mas sobretudo a financeira consiste verdadeiramente no único fenômeno global que ampliou e homogeneizou os padrões de comportamento das elites cosmopolitas mundiais nas últimas décadas. Pode-se dizer que este tipo de "financeirização global” produziu finalmente uma classe rentista internacional que extrapolou o redu- 
zido grupo da "aristocracia dos negócios" do mundo anglo-saxônico do final do século XIX até meados do século XX. ${ }^{4}$

A "securitização" privada destina-se a diminuir o risco das transações plurimonetárias, mas não diminui o "risco sistêmico" de propagação das crises nos vários mercados e países. Por isso, quando a crise se generaliza, faz-se uma "coordenação" dos riscos de ruptura sistêmica informalmente mediante a ação conjunta dos principais bancos centrais, capitaneados pelo FED americano.

Organizações como o FMI, por seu turno, têm um papel cada vez mais secundário no gerenciamento ou mesmo na monitorização das finanças internacionais globalizadas, atuando apenas como instrumentos de enquadramento político-financeiro dedicados à aplicação das políticas de "ajuste" fiscal e monetário aos países periféricos dependentes de endividamento externo.

\section{CRISES NOS MERCADOS FINANCEIROS MUNDIAIS}

Ao contrário do que reza a mitologia sobre os ataques especulativos contra as moedas nacionais, tais ataques não são motivados diretamente pelo estado dos chamados "fundamentos" econômicos de cada país, mas tendem a ser guiados primordialmente pela possibilidade concreta de os agentes financeiros (externos e internos) auferirem lucros pela especulação contra a moeda. Essa possibilidade, por seu turno, depende tanto de fatores estruturais como de fatores conjunturais ligados à capacidade de defender uma dada moeda.

A crise nos mercados financeiros mundiais é um processo que se desenvolve em três eixos convergentes: o geopolítico (movimentos de realinhamento e contenção no contexto da reafirmação da hegemonia norte-americana); o econômico (desequilibrios de preços, fiscais e de balanço de pagamentos - os chamados "fundamentos"); e o financeiro (desajustes de taxas de juros e de câmbio conduzindo a movimentos de especulação ou valorização patrimonial).

Esses movimentos (geopolítico, econômico e financeiro) marcaram a agenda político-econômica na década de 1990 com fatos de grande repercussão. O primeiro continente a ser afetado foi a Europa, com destaque para a crise do mecanismo cambial (ERM - Exchange Rate Mechanism) em 1992, onde estava em tela de juízo a preponderância do marco e da Alemanha na União Europeia - comprometida tanto pelos deslocamentos geopolíticos do Leste Europeu e da ex-URSS, quanto pela crescente instabilidade da praça financeira global de Londres - no contexto da tentativa de implantação, ainda em andamento, de uma moeda única - o euro.

Ao atingir a América Latina, no momento seguinte, a turbulência financeira mostrou sua face mais grave. Para além das pressões conjunturais que deflagraram o desequilíbrio nos mercados financeiros, os países latino-americanos apresentaram uma fragilidade externa estrutural em parte compreensível com base nos vínculos

\footnotetext{
${ }^{4}$ Ver Phillips (2002).
} 
de dominação política e de dependência do endividamento externo recorrente que os ligam às potências hegemônicas (primeiro a Inglaterra e depois os EUA).

A partir do afrouxamento da política monetária norte-americana, teve lugar uma onda de aumento da liquidez internacional no começo dos anos 1990, que se fez seguir por uma forte globalização dos mercados de juro e câmbio e pela saída em grande escala dos fundos de pensão Norte-americanos rumo aos mercados emergentes. Após tornar-se o segundo maior importador de capitais do mundo, o México reinaugurou um quadro de crise em fins de 1994. Seguiu-se uma situação de abalo praticamente permanente das contas externas na região, com problemas recorrentes de desequilíbrio cambial e fiscal. A propagação dá-se a partir da situação do balanço de pagamentos. As políticas cambiais e monetárias provocaram impactos sobre as taxas de juros e a expansão da dívida pública interna. A relação vai, portanto, do balanço de pagamento para o déficit fiscal, e não em sentido contrário como supõem os ortodoxos de turno.

Finalmente, em julho de 1997, a crise chegou ao Leste Asiático. Contra um pano de fundo que remonta ao movimento final de enquadramento japonês - a partir do estouro da bolha especulativa (bursátil e imobiliária) em $1990^{5}$ - e passa por uma acentuada flutuação do iene relativamente ao dólar norte-americano, ${ }^{6}$ os chamados 'novos tigres' sucumbiram sucessivamente às pressões especulativas que visavam explorar desajustes entre posições credoras e devedoras em dólar dos principais agentes econômicos e assimetrias institucionais no funcionamento dos mercados financeiros de países convertidos muito rapidamente em receptáculos para capitais de grande porte. A turbulência culminou com duas crises diferentes em suas implicações e mecanismos de propagação - a insolvência das grandes empresas e bancos coreanos, que diretamente provocaram perdas de agentes privados, e o crash de Hong Kong que se propagou globalmente aos mercados acionários de todos os países. Esse mesmo tipo de crise atingiu em ondas sucessivas países tão dessemelhantes como a Rússia (agosto de 1998), o Brasil (janeiro de 1999), a Argentina (2001) e os próprios Estados Unidos (2000-01).

O recurso preconizado pelo mainstream acadêmico aos chamados "fundamentos macroeconômicos" como variável explicativa exclusiva ou mesmo central ao entendimento da dinâmica dessas sucessivas crises fica desde logo desautorizado pelo exame da natureza dos fenômenos em questão, o que infelizmente não foi levado em conta pelas políticas preconizadas pelo FMI para as regiões em que interveio. Uma compreensão mais profunda da sua origem demanda, entretanto, que se olhe para além da mera combinação disfuncional de uma valorização patrimonial excessiva; de uma alavancagem financeira desproporcional ao patrimônio líquido de empresas e bancos; ou de uma paridade rígida com o dólar.

O cerne econômico destas contradições reside na natureza distinta dos movimentos da taxa de câmbio quando impulsionados por razões comerciais (atingir certas paridades vis-à-vis uma cesta de moedas relevantes em termos de comércio

\footnotetext{
${ }^{5}$ Ver Torres $F^{\circ}$ (1997).

${ }^{6}$ Ver Melin (1997).
} 
exterior) ou por razões financeiras (em resposta à arbitragem de juro e câmbio futuros pelos mercados financeiros). Com avaliações de risco e resultados completamente distintos e temporalidades assincrônicas entre ciclos mercantis e ciclos de ativos reais e financeiros, é fácil prever que os movimentos de capitais desregulados levam frequentemente a uma exacerbação das "desvalorizações competitivas” que termina por provocar crises cambiais. Quando estas decorrem de mudanças bruscas na paridade em relação ao dólar, tendem a propagar-se em cadeia pelos mercados cambiais e de ativos financeiros crescentemente interdependentes. ${ }^{7}$

Ao final dessas crises, das quais não se sai sem o recurso aos principais credores internacionais - sob a coordenação ou não do FMI, do BIS e, em última instância, do FED e do Tesouro norte-americano - raramente se verifica que os fundamentos macroeconômicos tenham voltado ao equilíbrio, até porque apenas com recurso a conjuros mágicos seria possível definir as taxas de câmbio e juros "de equilíbrio" nos atuais mercados globais. Este é o sentido profundo da contradição que jaz na base da fragilidade estrutural inerente ao próprio funcionamento da nova "desordem" financeira globalizada.

\section{OS DOIS CICLOS RECENTES E A CRISE FINANCEIRA NOS EUA}

\section{Uma visão geral}

Como fautores das políticas de desregulamentação e liberalização dos mercados de capitais nos últimos 25 anos, os EUA têm sido beneficiados em termos do crescimento de sua economia. Seus dois últimos ciclos de expansão, 1983-89 e 1992-2000, e sua recente recuperação, 2002-03, estão expostos no Gráfico 1.

Gráfico 1: Taxa de Crescimento Real do Produto Interno Bruto - EUA

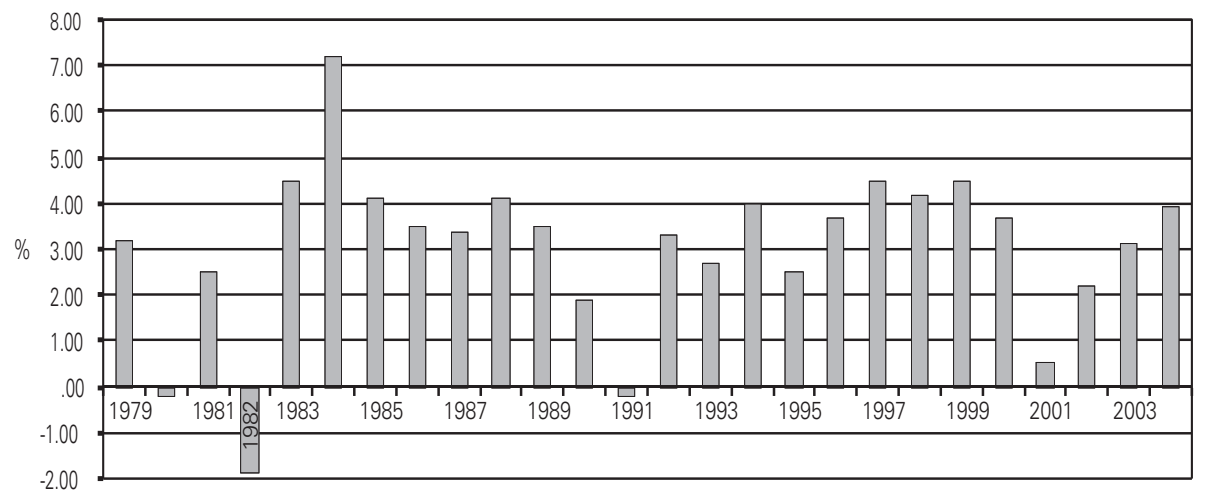

Fonte: Bureau of Economic Analysis (BEA). (http://www.bea.gov).

${ }^{7}$ Ver Miranda (1998). 
De modo geral, pode-se dizer que a década de 1980 começou sob a égide do $2^{\circ}$ choque do petróleo (1978) e do choque de juros (1979) desencadeado pela política do Fed. Ambos os eventos mergulharam a economia mundial, que já vinha de um período de estagflação, numa recessão forte com inflação alta. O governo Reagan foi o primeiro a realizar medidas antidepressivas. Já a partir de 1983, a economia norte-americana retomara sua trajetória de crescimento, que se sustentou por mais sete anos, sendo interrompida apenas em 1991, quando os EUA entraram em nova recessão.

Por sua vez, a década de 1990 começou com a guerra no Golfo (1991) e com uma forte recessão na economia norte-americana (1991), que repercutiu sobre toda a economia mundial. Em 1992, apesar da retomada do crescimento, os republicanos deixaram a Casa Branca. Os EUA iniciaram naquele momento mais um ciclo de expansão (1992-2000), o qual apresentou um fôlego ainda maior que o anterior, e cuja desaceleração ocorreu apenas em 2001, de modo relativamente mais tênue que as duas anteriores (1980-82 e 1990-91). A ver pelos dados dos anos de 2002-03 e do primeiro trimestre de 2004, a economia norte-americana mais uma vez parece estar reagindo bem à conjuntura de desaceleração.

Do ponto de vista da economia mundial, a década de 1990 transcorreu com fortes assimetrias: crescimento significativo da economia Norte-americana a partir de 1992; recuperação lenta da economia europeia; ondas sucessivas de crises na América Latina, na Rússia e no Leste Asiático; crise profunda na África (em desintegração); além da estagnação econômica japonesa durante toda a década. Só a China aproveitou a globalização generalizada e a expansão da economia Norte-americana dos anos 1990 levando a cabo um projeto de integração dual e cuidadoso à economia global, com apoio nas zonas de exportação dominadas pelas filiais norte-americanas. ${ }^{8}$ A Índia ficou fora do "jogo global" e cresceu apoiada em um projeto escalonado de incorporação de tecnologia e da população ao crescimento da renda e do mercado interno.

Deve-se ter claro que os ciclos econômicos norte-americanos comandam os ciclos mundiais apenas durante as fases de crise e estagnação. As reversões de suas fases ascendentes contaminam praticamente toda a economia mundial. No entanto, quando inauguram novo ciclo de expansão, os Estados Unidos trazem consigo apenas alguns poucos "acoplados". As advertências de Prebisch (1949), acerca do problema de se ter uma economia como a norte-americana no papel de centro dinâmico principal do sistema mundial, nunca foram tão evidentes como no período recente.

\section{A suposta fraqueza da economia norte-americana}

O modo pelo os Estados Unidos se inserem na economia mundial é o primeiro ponto a ser examinado para se entender o dinamismo da economia norte-americana nos últimos 25 anos. O Gráfico 2 expõe a gigantesca e quase permanente entrada líquida de capitais (hot money e IDE) nos EUA ao longo desse período, atraídos

${ }^{8}$ Ver Medeiros (1999). 
pela violenta especulação em bolsa, e que vem permitindo a manutenção de enormes déficits em transações correntes, sem qualquer contrapartida sobre sua política econômica.

Para todo o período (1980-2003), o déficit só desapareceu, por pouco tempo, quando a economia se encontrava em recessão aberta, em 1980-82 e 1990-91. No entanto, agravou-se desmedidamente a partir de 1996 no auge do ciclo de consumo e investimento. Em 2001, mesmo com a estagnação econômica $(0,3 \%$ de crescimento do PIB em termos reais), o saldo em transações correntes permaneceu praticamente no mesmo patamar do ano anterior, correspondendo a $71 \%$ do déficit global naquele ano. Já nos anos seguintes (2002-03), a tendência de deterioração permaneceu, assim como a impressão de que inexistem mecanismos que os corrijam, uma vez que capitais de todo o mundo continuam tratando os mercados financeiros dos Estados Unidos como espaço privilegiado para sua valorização financeira.

Gráfico 2: Balanço de Pagamentos dos EUA (US\$ milhões)

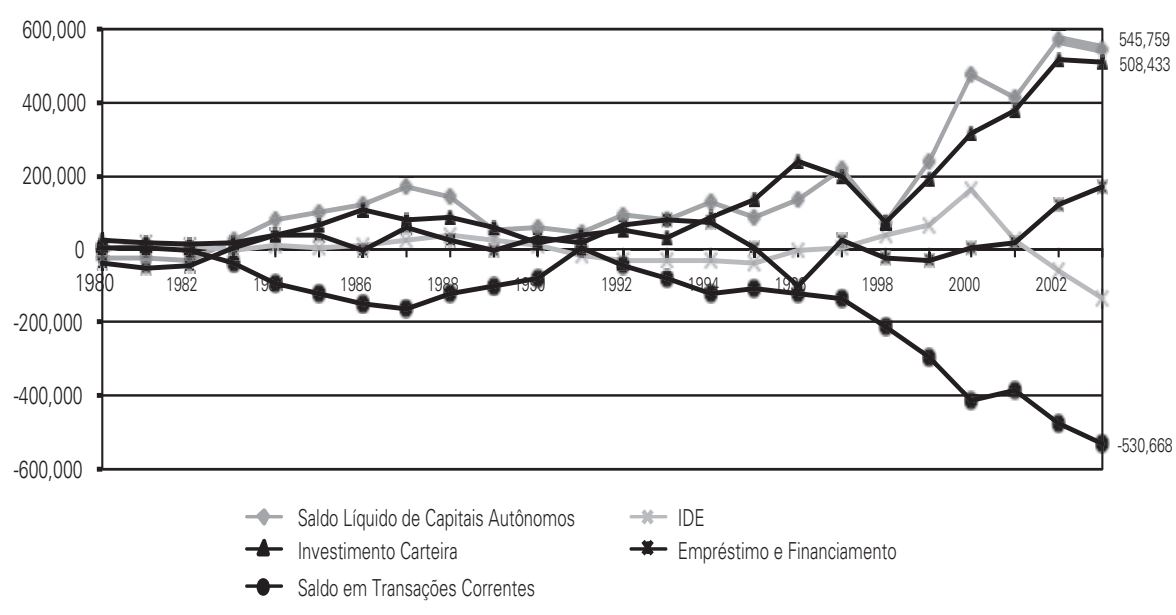

Fonte: Bureau of Economic Analysis. (http://www.bea.gov).

Para todo o período em questão, os déficits em transações correntes foram financiados fundamentalmente pela maciça entrada de investimentos em carteira e, durante o período de 1996 a 2001, também pela forte entrada de investimento direto estrangeiro (IDE), atraídos pela violenta especulação em bolsa, sobretudo para fusões e aquisições de empresas estrangeiras. ${ }^{9}$ Fenômeno que o próprio Greenspan - presidente do FED - denominou de "exuberância irracional". A partir de 2002, com o estouro da bolsa (sem crash), o IDE passou a ser negativo, mas foi compensado pela entrada de capitais na forma de "empréstimos e financiamentos".

A ideia central é que o privilégio obtido pelos EUA com as políticas de dolari-

\footnotetext{
${ }^{9}$ Ver relatório UN/UNCTAD (2000).
} 
zação e desregulação dos mercados consolidou um poder financeiro estrutural, sem precedentes históricos, manifesto em sua capacidade de absorver parte expressiva da riqueza financeira mundial. Esse poder, cuja égide tem sido a posição cardeal de sua moeda nos mercados financeiros internacionais e cuja originalidade está na inexistência de qualquer lastro para sua moeda, permite-lhes financiar há mais de duas décadas a expansão de seu consumo doméstico, do investimento privado e do gasto público por meio de uma enorme capacidade de endividamento (externo e interno), atualmente sem limite aparente. Não é por acaso, portanto, que os Estados Unidos não têm demonstrado qualquer interesse em abrir mão dos seus ganhos de arbitragem e do seu poder de "seignorage" para arquitetar uma nova ordem econômica mundial negociada democraticamente e menos assimétrica.

A capacidade de endividamento da economia norte-americana não guarda relação alguma com seus fundamentos macroeconômicos, os quais por sinal são no mínimo preocupantes para os padrões consagrados pelo FMI. Apesar disso, continua-se insistindo numa suposta semelhança entre os problemas macroeconômicos enfrentados pelos EUA e os problemas dos países da periferia (emergentes), cujas moedas nacionais são inconversíveis internacionalmente.

A despeito das desvalorizações do dólar e do crescente endividamento externo e fiscal, a economia norte-americana tem sido um dos principais receptores de capitais dos últimos 25 anos. Não existem restrições sobre as contas externas dos EUA, típicas dos países deficitários, justamente porque os agentes de todo o mundo aceitam manter suas posições em dólar, apesar do comportamento dos mercados nacionais de câmbio. Com efeito, não se criam mecanismos de pressão para correção dos gigantescos desajustes macroeconômicos da economia dos EUA. Esses desequilíbrios são, portanto, transferidos aos demais países, que passam a acumular enormes reservas em dólares.

Estar denominado em dólar garante aos agentes econômicos acesso aos mercados mais líquidos e profundos de todo o sistema financeiro internacional. O dólar cumpre hoje a função mais importante de moeda financeira. As qualidades de qualquer ativo financeiro, em termos de sua liquidez e segurança, variam de acordo com sua referência monetária (unidade de conta) (Tavares e Melin, 1997).

Neste cenário, são os títulos da dívida pública dos Estados Unidos (U.S. Treasuries) que ocupam posição de destaque. Estes são os mais nobres de todo o sistema financeiro internacional e estão na base de todo o processo de securitização, funcionando como lastro principal das operações financeiras. Suas características singulares são risco de crédito mínimo, elevadíssima liquidez, amplo espectro de maturidades e desenvolvida infraestrutura de mercado. Tais características garantem aos U.S. Treasuries atribuições exclusivas dentro do sistema financeiro internacional. São indispensáveis à administração do risco privado e à própria estabilidade e eficiência do sistema internacional, pois cumprem funções vitais, como a de porto seguro, provedor das taxas de juros de referência, veículo de hedge e importante instrumento para investimentos de longo prazo e para a administração de liquidez.

Os mercados de dívida pública dos EUA são os mais líquidos e profundos do mundo. Seu tamanho e profusão tornam os demais mercados, de ativos públicos 
ou privados, imagens em miniatura. Neste sentido, devem ser compreendidos como um elemento-chave do poder financeiro estrutural dos Estados Unidos, expresso em sua enorme capacidade de sucção da riqueza financeira mundial. Para se ter uma ideia, de acordo com dados do BIS, as emissões de títulos de longo prazo pelo governo dos EUA (Bonds), em junho de 2000, correspondiam a: i) 23,61\% das emissões de dívida de longo prazo de todo o mundo (públicas e privadas); ii) $50,29 \%$ de todo estoque de títulos de longo prazo que foram emitidos nos EUA (pública e privada); e iii) 43,74\% das emissões de longo prazo do setor público de todo o mundo. ${ }^{10}$

Os títulos da dívida pública norte-americana permitiram o ajustamento das carteiras dos bancos e empresas, quando estes enfrentaram enormes problemas financeiros no início dos anos 1980 (em função do choque dos juros de 1979 e da subsequente crise na Periferia) e nas demais crises que se seguiram. Não são as necessidades fiscais do governo dos EUA que explicam tamanha profusão e crescimento do estoque da dívida pública a partir dos anos 1980, muito embora tenha havido significativa expansão dos gastos militares no período Reagan financiados com emissão de dívida. No entanto, são as demandas financeiras dos agentes de todo o mundo (fly to quality) e o papel do governo dos Estados Unidos como principal emprestador de última instância do sistema financeiro internacional que permitem compreender a explosão do estoque da dívida pública dos EUA nos últimos 25 anos.

\section{CONSUMO, INVESTIMENTO E GASTO PÚBLICO NOS DOIS CICLOS RECENTES}

Internamente, a reorganização do sistema habitacional no início da década de 1980, através do refinanciamento e repactuação das dívidas do setor, o qual passava por violenta crise financeira, permitiu a recuperação do investimento pela construção civil, como mostra o Gráfico 3. A reação do investimento residencial conseguiu puxar os demais componentes do investimento privado já em 1984. Aliás, pode-se depreender que em absolutamente todas as fases de retomada do crescimento (1983, 1992 e 2002) o investimento residencial foi o componente mais dinâmico, sempre liderando a recuperação das taxas gerais de investimento. Por outro lado, muitas vezes, é também o primeiro a entrar em crise e a puxar consigo os demais componentes (1979 e 1988-89).

O ciclo de crescimento dos EUA na década de 1990 foi conduzido até 1996 por uma onda de investimentos na "velha", mas, sobretudo, na "nova economia", à qual se acoplou o crescimento significativo do consumo. A expansão do investimento em equipamentos e software (modernização) nos EUA, por exemplo, apresentou enorme dinamismo, com uma taxa de crescimento médio de $11,5 \%$ ao ano para todo o ciclo dos 1990 (1992 e 2000). Tal profusão foi acompanhada por uma

\footnotetext{
${ }^{10}$ Ver Metri (2003: 98).
} 
enorme especulação em bolsa (com será visto adiante), em razão dos processos de fusões e aquisições e do próprio boom da economia na década de 1990, que facilitaram os financiamentos dos investimentos privados via mercado acionário.

Gráfico 3*: Taxa de Crescimento do Investimento Privado Bruto - EUA

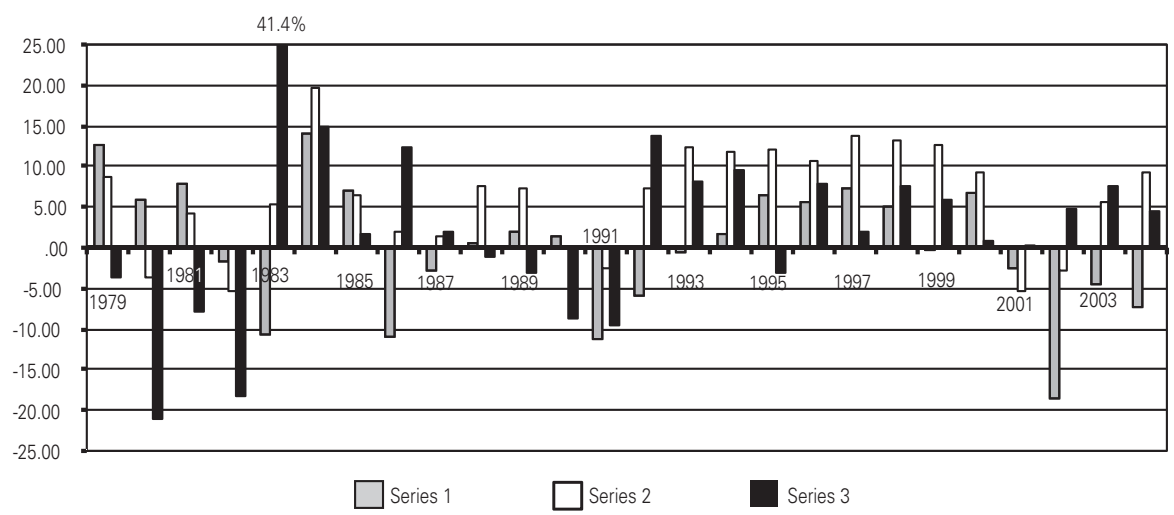

* A taxa de crescimento do "investimento residencial" em 1983 foi de 41,4\%. Para não prejudicar a visualização do gráfico, optou-se apenas por indicá-la. Fonte: Bureau of Economic Analysis. (http://www.bea.gov).

Em 2001, contudo, as taxas de investimento despencaram, destaque para os investimentos em "estrutura" (capacidade produtiva). A resposta do governo dos EUA conseguiu conter a deflação dos ativos financeiros e a desaceleração da economia naquele ano. Na recuperação, já em 2002, destaque mais uma vez para o investimento "residencial", o qual foi seguido, no ano de 2003, pelo investimento em "equipamentos e software".

Por sua vez, o consumo privado nos EUA tem como componente mais dinâmico os "bens duráveis", dentre os quais se destacam "imóveis" e "automóveis". Os "duráveis" sempre estiveram acoplados às fases de boom do investimento, dando fôlego aos ciclos econômicos recentes, e reforçaram a tendência de desaceleração da economia nas fases de crise. No entanto, na desaceleração de 2001, o consumo de duráveis ajudou a evitar uma desaceleração ainda maior da economia, ao alcançar um crescimento de $4 \%$.

De acordo com dados do FED, ${ }^{11}$ os ciclos de crescimento do investimento e do consumo privado foram financiados, sobretudo pelo endividamento das empresas e famílias, principalmente nos 1990s, por conta da violenta especulação em bolsa. A novidade surgiu no ano de 2000, quando ocorreu uma reversão do ciclo de endividamento das corporações, em razão do enorme grau de fragilidade financeira e entrelaçamento patrimonial e creditício alcançado, na segunda metade dos anos 1990, pelas grandes empresas (como será analisado mais adiante). O endividamento das famílias, porém, permaneceu explosivo até 2002, o que é explicado pelas

${ }^{11}$ Ver Federal Reserve Bank, Flows of Fund Account of the United States, Second Quarter 2002. 
taxas de juros negativas, dadas para recuperar a indústria de bens de duráveis e de construção, assim como para impedir uma recessão aberta.

A combinação de um sistema financeiro altamente desenvolvido com uma política monetária extremamente frouxa vem permitindo o fácil financiamento dos gastos privados durante as fases de boom, como também as rodadas de renegociação dos contratos financeiros entre credores e devedores nas fases de desaceleração e crise.

Olhando para os gastos do governo, depreende-se que o seu mais importante componente anticíclico foram, e continuam sendo, as transferências governamentais (transfer payments). Os gastos (consumo e investimento) militares nem sempre atuaram para a reversão das crises, como muitos analistas supõem. Eles tiveram importância significativa como componente anticíclico apenas durante o governo Reagan. Os gastos em defesa aumentaram sua participação no PIB em 1,7 ponto percentual entre 1979 e 1985. Já durante a recessão de 1991, a despeito das aventuras bélicas de Bush (pai) no Golfo Pérsico, a participação dos gastos militares permaneceu estável em relação ao ano anterior (1990). Mas, no geral, ela caiu progressivamente (de 7,4\% do PIB em 1987), atingindo seu nível mais baixo para o período em questão no ano de 2000 (3,8\% do PIB). Na desaceleração de 2001, com Bush (filho) no comando da máquina de guerra norte-americana, a participação dos gastos militares voltou a crescer, no entanto, de forma não muito significativa, de 3,8 \% em 2002 para 4,5\% do PIB em 2003. ${ }^{12}$

As transferências governamentais, durante a crise do início dos anos 1980, aumentaram sua participação no PIB em 1,7 ponto percentual; já na recessão de 1991, elas cresceram também de 1,7 em um ano; e, na desaceleração de 2001, expandiram sua participação praticamente na mesma proporção das anteriores, em 1,6 ponto percentual. As evoluções dos mais relevantes componentes das transferências do governo ao longo de 1980-2001 foram dos gastos com saúde e income security. Em suma, nas últimas décadas, o keynesianismo Norte-americano ainda sobrevive no que se refere aos gastos militares do governo, mas sobretudo do que restou de seus gastos sociais, principalmente na forma de income security.

\section{A CRISE FINANCEIRA DE 2001: O ESTOURO DA BOLHA}

Como consequência do "boom" da economia norte-americana nos anos 1990, ocorreu uma valorização expressiva do mercado acionário. A bolha especulativa que se seguiu a 1996 é explicada em grande parte por uma onda de fusões e aquisições de grandes empresas e bancos. Por exemplo, houve a formação do Citigroup, fusão do Citicorp com o Travelers Group; do Bank América, fusão do Bank América com o Nation Bank; e do Chase Manhattan, fusão do Chase Manhattan com o Wells Fargo (Roberts, 2000: 76).

No entanto, o mesmo não ocorreu com as megafusões dos setores de telecomu-

${ }^{12}$ Ver Bureau of Economic Analysis http://www.bea.gov. 
nicações, mídia e petróleo (WorldCom, Time-Warner e Mobil-Exon), onde as indústrias ficaram mais dispersas e competitivas com o surgimento de novas empresas.

A massa de endividamento interno e externo da economia norte-americana funcionou na década de 1990 como uma máquina de sucção e atração de capitais, que financiaram uma onda de expansão (a economia turbinada) e de centralização de capital. Nesse período houve "a maior valorização das ações em todos os tempos nos Estados Unidos. A relação preço-lucro em abril de 2000 era $30 \%$ mais elevada do que a apresentada em 1929" (Belluzzo, 2002). Além disso, "no período de 20 anos que antecedeu o colapso de 1929 , os preços cresceram menos de $100 \%$ em termos reais, ainda que, nos últimos cinco anos, tenha sido formidável a aceleração - 241\% entre 1924 e 1929. Já nos 20 anos anteriores a 2000, quando se registrou o pico do bull market do ciclo recente, os preços evoluíram 571\%" (op. cit. 2002).

Por outro lado, a massa de endividamento e de acumulação patrimonial funcionou como um mecanismo de destruição de capital financeiro na reversão dos ciclos de valorização, sem precedentes na história do capitalismo. A desvalorização da riqueza financeira entre 2000 e 2002 foi muito maior em termos absolutos e relativos ao PIB norte-americano, do que a ocorrida na crise de 1930. O estouro da bolha de Wall Street, que atingiu o auge em 2000, não foi, porém, precedida por um crash. A reversão do ciclo de ativos, do comércio mundial e do IDE a partir das tendências recessivas da economia norte-americana já ocorrera de forma acentuada no $2^{\circ}$ trimestre de 2001, antes mesmo do ataque terrorista.

Poucos prestaram atenção ao fato de que as megafusões de corporações e bancos e a desregulação final entre os mercados de crédito e de capitais em Wall Street contribuíram para o auge da gigantesca bolha especulativa. $\mathrm{O}$ que à altura parecia ser um excelente negócio e permitiu uma enorme centralização de capital financeiro, trouxe, com a reversão do ciclo, os prejuízos correspondentes. Em relação ao mercado financeiro global, infere-se, de 05/2000 a 07/2002, uma perda patrimonial de cerca de US\$11,5 trilhões (valor maior que toda a produção dos EUA em 2001). As novas subscrições caíram 70\% em um ano, de US\$ 356 bilhões em 2000 para US\$ 110 bilhões em 2001. E apenas $8 \%$ do investimento empresarial em 2001 foram financiados pelas bolsas, contra 27\% em 2000 (Costa, 2002).

$\mathrm{Na}$ verdade, o ataque terrorista de 2001 aparentemente salvou Wall Street de um crash semelhante ao de 1930. Depois do ataque, o FED, em pronta resposta, coordenada com os bancos centrais do G7, sustentou o dólar com injeções de liquidez de cerca de US\$ 400 bilhões e forçou a baixa escalonada das taxas de juros dos países do G7, sobretudo dos títulos de curto prazo do Tesouro dos EUA. O governo norte-americano interrompeu sua trajetória de queda, não apenas para dar liquidez e segurança ao sistema privado, mas também para assegurar os gastos fiscais necessários à reconstrução de Nova York e às ações militares, já executadas no Afeganistão e na recente guerra no Oriente Médio. Apesar da desvalorização do dólar e da baixíssima taxa de juros de curto prazo, não houve queda nos títulos do Tesouro de longo prazo. A política de desvalorização do dólar foi praticada a pretexto de evitar a deflação de ativos, aproveitando que o euro ainda é uma moeda 
financeira internacional de menor peso global que o dólar. O yen, por sua vez, sem autonomia para desvalorizar, não pode disputar com o dólar na Ásia.

As políticas macroeconômicas não dissolvem o risco financeiro sistêmico a que se submeteu o centro principal do capitalismo mundial ao permitir o entrelaçamento patrimonial e creditício entre os seus dez maiores bancos e as suas principais corporações. As operações financeiras "off the records" geraram não apenas balanços corporativos fictícios, mas uma alavancagem de crédito e um descasamento entre ativos e passivos sem precedentes, que introjetam no núcleo duro do sistema uma situação de risco imanejável do ponto de vista das políticas convencionais. Os problemas de digestão da crise dos conglomerados financeiros japoneses são imagens pálidas perto das dificuldades que esperam os grandes conglomerados norte-americanos nesta primeira década do século XXI.

Pode-se dizer que o keynesianismo americano ainda está vivo nas políticas macroeconômicas dentro da economia norte-americana, mas nem tanto do ponto de vista da reconstrução de um novo sistema monetário internacional mais equidistante da potência hegemônica. Vale dizer, mesmo em crise os EUA querem manter a hegemonia do dólar e o seu poder de "coordenação forçada" sobre o sistema financeiro global, o que não puderam fazer na crise de 1930, por serem uma economia muito fechada e credora do resto do mundo. Hoje, quando o dólar desvaloriza, são os demais países credores e não o devedor soberano que pagam a conta dos desequilíbrios externos norte-americanos, como já se verificou na segunda metade da década de 1980.

Nesta desordem financeira global, a China destaca-se como um país superavitário em relação aos EUA e ao Japão e devedora das grandes empresas globais que para lá foram em busca de plataformas de exportação de mão de obra e de mercado interno em expansão. Os fluxos de IDE provocaram uma divisão intrafirmas do comércio internacional que favoreceu sobretudo a Ásia nas décadas de 1980 e 1990. A partir de agora é provável que as empresas transnacionais tendam a investir cada vez mais no enorme mercado interno chinês.

Sobre as possibilidades de se retomar rapidamente um novo ciclo de crescimento econômico, cabe ressaltar, no entanto, que o atual keynesianismo bélico não produzirá os mesmos resultados internos e globais da "Guerra nas Estrelas" de Reagan. Na melhor das hipóteses, se o atual ataque ao Iraque durar pouco e o déficit fiscal não tiver de ser financiado com o aumento dos juros, a guerra de Bush (filho) poderá provocar resultados econômicos semelhantes aos da guerra do deserto de Bush (pai).

Quaisquer que sejam os desdobramentos da crise política-econômica atual, os dias da "globalização benigna" sob a hegemonia norte-americana estão definitivamente encerrados. Estamos presenciando uma degenerescência da "ordem mundial global" estabelecida no após Segunda Guerra Mundial, sobre cuja "Reforma” só o próprio centro imperial poderá tomar a iniciativa. 


\section{A PASSAGEM DA HEGEMONIA AO IMPÉRIO - OS EUA COMO PODER UNIPOLAR?}

As potências hegemônicas ao longo da história sempre se afirmaram pela supremacia das armas e do dinheiro, e apresentaram em geral uma vocação imperial irresistível que só terminava com o enfrentamento com outras potências. Tentaram, quase sempre sem sucesso prolongado, enquadrar o "mundo" do qual tinham sido os fiadores da "Pax", impondo-lhes tratados geopolíticos e uma estrutura de Direito, privado e público, com pretensões universais e civilizatórias.

A tentativa mais abrangente foi a executada pelos EUA no pós-Segunda Guerra mundial. Na condição de grande potência vencedora, os EUA tornaram-se rapidamente o centro hegemônico do sistema capitalista e os fiadores da Pax Americana. A hegemonia Americana foi considerada benigna tanto para os processos de descolonização dos países submetidos aos velhos impérios quanto para os ex-adversários da guerra, Alemanha e Japão. Estes conduziram, depois da reconstrução com o apoio dos EUA, suas economias a elevadas taxas de crescimento e compuseram a famosa tríade, o G3, o núcleo duro do G7 cuja coordenação liderou as tendências da economia mundial durante as "três décadas douradas" do pós-guerra.

A hegemonia econômica norte-americana foi-se estendendo na medida em que países importantes aderiram ao sistema multilateral e as filiais das empresas e bancos norte-americanos foram se expandindo pelo mundo através de redes comerciais, financeiras e de comunicações cruzadas com o investimento direto em plantas manufatureiras e matérias-primas estratégicas. Depois dos choques do petróleo e de juros do final da década de 1970 e das sucessivas crises financeiras das décadas seguintes, os "consensos" sucessivos emanados de Washington foram se tornando cada vez mais duros e a hegemonia econômica foi perdendo o caráter benigno. Ao mesmo tempo que é permissiva para os interesses do capital das grandes corporações e protecionista para vários setores da economia norte-americana, tenta sistematicamente ditar as regras para os outros países (sobretudo os periféricos) com as políticas neoliberais.

A hegemonia politica estabeleceu-se na Europa, com o enquadramento dos aliados pela OTAN e a política de enfrentamento com a URSS, a chamada Guerra Fria. Na Ásia, com a desmilitarização do Japão, a Guerra da Coreia, a intervenção na Indonésia e a Guerra do Vietnã. Finalmente no Oriente Médio, desde a entrada da $7^{a}$ Esquadra no Mediterrâneo em 1954, os EUA passaram a mover o tabuleiro geopolítico da região, considerada estratégica pelas imensas reservas de petróleo, em substituição das antigas potências inglesas e francesas. Foram mudando de alianças rapidamente e depois da guerra do Egito com Israel, este passou a ser um país-chave no domínio geopolítico norte-americano do Oriente Médio.

$\mathrm{Na}$ década de 1970, surgiram os primeiros sintomas de uma possível crise de hegemonia norte-americana. A derrota do Vietnã, a ruptura do padrão dólar-ouro e a perda da concorrência do "made in America" para o "made in Japan", ameaçaram a autoestima e a imagem internacional da grande potência. As crises do sistema capitalista internacional, que passaram a ocorrer com maior frequência 
depois da ruptura do sistema de Bretton Woods e da implantação do padrão "dólar flutuante", levaram a rupturas de contratos e quebras financeiras de Estados e empresas que obrigam a mudar as "regras do jogo econômico internacional", por algum tipo de pactuação entre os governos dos países centrais (G3 e G7) e das respectivas periferias.

A retomada dura da hegemonia global deu-se no governo Reagan no início da década de 1980 com a diplomacia do dólar forte e a diplomacia das armas. Porém, houve uma mudança na sua natureza. O aumento desmedido do poderio tecnológico-militar dos EUA avançou radicalmente desde a ofensiva contra o "Império do Mal". A derrocada da URSS e a "neutralização" da China, como parceira incorporada à economia global, mudaram a natureza da hegemonia na direção de uma escalada global e territorial. A tentativa da União Europeia de se contrapor como um bloco unido à hegemonia americana até agora não tem logrado sucesso.

A generalização das reformas neoliberais, além de mudarem a natureza da hegemonia norte-americana do ponto de vista geoeconômico, deram-lhe um caráter ideológico de "pensamento único" e converteram o Dinheiro e o Mercado em pilares da "Cultura Ocidental". Desde então vem ocorrendo uma convergência entre a violência geopolítica, a violência financeira e a violência social, que já provocou várias crises tanto no centro como na periferia do sistema internacional e retirou o caráter benigno e a justificativa "moral e civilizatória" da hegemonia norte-americana como garantidora da "Ordem Mundial".

Do ponto de vista geopolítico, desde a implementação da "diplomacia" das armas, a Pax Americana está em plena expansão imperial. Depois de estender-se do Oriente Médio aos Bálcãs - cumprindo finalmente a direção geopolítica que Winston Churchill recomendara durante a Segunda Guerra Mundial para conter a Rússia - encaminhou-se na direção da Ásia Menor, no interior das suas fronteiras asiáticas. Como tendência de longa duração, a superpotência está tentando ir além das fronteiras onde os antigos impérios pararam. Por outro lado, a nova "doutrina de segurança", autorizando guerras preventivas sem apoio em qualquer fórum internacional e sem o acordo das demais potências que participaram na Segunda Guerra Mundial, desmonta a arquitetura política estabelecida no pós-guerra.

A passagem da hegemonia ao Império não reside somente no papel de gendarme substituto da violência dos anteriores impérios coloniais já que isso foi feito progressivamente a partir do pós-guerra. O paradigma do novo "Poder unipolar" não é o imperialismo clássico de Políbio ou o concerto de Vestefália nem mesmo da Pax Brittanica que buscava a hegemonia através do "equilíbrio do poder" entre as demais potências.

A nova "doutrina de segurança" norte-americana apoia-se na ideia, defendida pelos "falcões" civis do Departamento de Defesa - iniciada com os assessores de George Bush (pai) - de que não existe nem deve existir, num futuro visível, qualquer potência à altura dos EUA e que o mundo multipolar das grandes potências deve terminar. Trata-se de uma proposta absurda de ideologia totalitária de organização global a partir de uma "ordem unipolar" que pode ser reorganizada periodicamen- 
te ao sabor dos interesses, da ideologia e até das idiossincrasias de um novo poder imperial.

O ataque ao Iraque está invocando o direito à intervenção unilateral, não sujeita a regras gerais de Direito Internacional moderno expressas na Carta das Nações Unidas, nem a negociações diplomáticas com as demais potências do Conselho de Segurança. Do ponto de vista geopolítico, os EUA dispensaram a colaboração e o alinhamento das potências europeias continentais, desmantelaram a OTAN e puseram em xeque a ONU. Arrogam-se, além disso, o direito de impor unilateralmente as condições da paz e a participação das empresas norte-americanas na reconstrução, supostamente paga pela retomada da produção do petróleo iraquiano. A geoeconomia do petróleo é vital para os interesses da economia mundial, mas atinge muito mais os interesses da Europa continental do que dos próprios EUA, que dispõem de outras fontes de abastecimento no continente americano. Portanto, as razões geopolíticas de dominação no Oriente Médio parecem ir além dos interesses econômicos poderosos de controlar as reservas iraquianas e caminham na direção de levar a Pax Americana ao centro do mundo euro-asiático.

A reação ao expansionismo e arrogância do Império americano além de produzir uma combinação explosiva de protestos e violência em todos os planos, encontra resistências crescentes na maioria das potências que até agora compuseram o Conselho de Segurança da ONU. Põe em risco a própria União Europeia, tão duramente conquistada, e as outras potências nucleares como a China e a Rússia. A própria recuperação da economia mundial (começando pela Norte-americana) está ameaçada se ocorrer uma nova corrida armamentista e aumentar a proliferação de armas químicas e nucleares. A desordem mundial e as guerras não favorecem a economia mundial como se viu claramente no período 1914-45 e nas três guerras curtas do Oriente Médio.

A médio prazo é de esperar que a arquitetura de uma "Nova Ordem Mundial” acabará tendo de ser refeita em novas bases multilaterais; embora os EUA continuem comandando a hierarquia como potência dominante, terão de refazer uma nova Pax Americana. O domínio unipolar do mundo não é sustentável nem compatível com qualquer noção de paz negociada e de civilização. Tampouco é sustentável uma ordem capitalista que ao mesmo tempo se pretende "global" mas não pode anular a existência de Estados nacionais seculares e, portanto, é obrigada a repactuar periodicamente novas regras de convivência.

\section{CONCLUSÃO}

A globalização não é uma tendência antiga ligada a uma crescente interdependência das economias do mundo. No quadro das ondas de internacionalização do capital, trata-se de um fenômeno novo. Desde a consolidação dessa nova ordem globalizada e desregulada, as crises financeiras se desenvolveram em três eixos convergentes: o geopolítico, o econômico e o financeiro. E, ao contrário dos demais países, os EUA têm sido extremamente beneficiados por ela. Seus dois últimos ciclos 
de expansão e sua recente recuperação mostram isso. As políticas de dolarização e desregulação dos mercados consolidaram um poder financeiro estrutural que lhes permite financiar sem restrições aparentes a expansão de seus componentes de gasto (público e privado).

O "blow back" das finanças globalizadas e desreguladas em 2001 acabou por atingir os próprios EUA, com uma grave crise financeira interna. As iniciativas para enfrentar a crise não dissolveram o risco sistêmico, pois não resolveram o problema do entrelaçamento patrimonial e creditício entre os maiores bancos e corporações. As operações "off the records" produziram balanços corporativos fictícios, alavancagem de crédito e descasamento entre ativos e passivos.

Em sentido mais amplo, a globalização pode ser compreendida como parte do quadro de transformações da natureza da hegemonia norte-americana no sistema mundial, iniciadas no governo Reagan. Da hegemonia ao Império, as violências geopolítica, financeira e social cresceram acentuadamente, sobretudo depois da generalização das reformas neoliberais nos 1990 s e da nova "doutrina de segurança” dos EUA. No entanto, é difícil imaginar qualquer tipo de paz estável a partir de um projeto de dominação unipolar, como também é pouco provável a sustentação de uma ordem econômica liberalizada e globalizada estruturada sobre um sistema interestatal competitivo.

\section{REFERÊNCIAS}

BELLUZZO, L. G. (2002) "Exuberância irracional”. Carta Capital, n 198, ano VIII, 17/7/2002.

BRAGA, J. C S. (1997) "Financeirização global”. In TAVARES, M. C. \& FIORI, J. L., orgs. Poder $e$ Dinheiro, Petrópolis: Ed. Vozes.

BRETT, E. A. (1985) The World Economy since the War: The Politics of Uneven Development. New York: Praeger Publishers.

CHESNAIS, F. (coord.) (1996) La Mondialisation Financière. Paris: Syros.

CINTRA, M. A. (2004), “Papel do dólar ainda confere poder extraordinário aos EUA”. Disponível em: www. desempregozero.org.br/artigos/.

COSTA, A. M. C. (2002) “Onze trilhões perdidos”. Carta Capital, n 198, ano VIII, 17/7/2002.

EICHENGREEN, B. (2000) A Globalização do Capital: Uma História do Sistema Monetário Internacional. São Paulo: Editora 34.

FIORI, J. L. (1999) “Estados, moedas e desenvolvimento”. IN FIORI, J. L. (org.) Estados e Moedas no Desenvolvimento das Nações/ Petrópolis: Editora Vozes.

GOWAN, P. (1999) The Global Gamble - Washington's Faustian Bid for World Dominance. New York: Verso.

HOBSON, J. A. (1983) A Evolução do Capitlismo Moderno. São Paulo: Editora Abril.

JOHNSON, C. A. (2001) Blowback - The Costs and Consequences of American Empire. New York: Owl Books.

KAPSTEIN, E. B. (1994) Governing the Global Economy: International Finance and the State. Cambridge, MA/London: Harvard University Press.

MEDEIROS, C. A. (1999) “China: entre os séculos XX e XXI”. In FIORI, J. L. (org.) Estados e Moedas no Desenvolvimento das Nações. Petrópolis: Ed. Vozes.

MELIN, L. E. (1997), “O enquadramento do Iene: A trajetória do câmbio japonês desde 1971”. In TAVARES, M. C. \& FIORI, J. L. (org.) Poder e Dinheiro: Uma Economia Política da Globalização/ Petrópolis: Ed. Vozes. 
METRI, M. M., (2003) Hierarquia e Competição entre Estados Nacionais no Atual Sistema Monetário Internacional, Tese de Mestrado, IE/UFRJ.

MIRANDA, J.C. (1998) "A dinâmica financeira da crise asiática". Revista de Política Exterior, março.

OCAMPO, J. A., coord, (2002) Globalización y Desarrollo. Vigesimonoveno período de sesiones. Brasília, Brasil, 6 al 10 de mayo de 2002. CEPAL, Santiago do Chile: Cepal.

PHILLIPS, K. (2002) Wealth and Democracy: A Political History of the American Rich. New York: Broadway Books.

PREBISCH, R. (1949) “O desenvolvimento econômico da América Latina e alguns dos seus principais problemas”. Revista Brasileira de Economia, 1949.

ROBERTS, R. (2000) Por Dentro das Finanças Internacionais: Guia Prático dos Mercados e Instituições Financeiras. Rio de Janeiro: Jorge Zahar Editores.

STALLINGS, B., editor (1995) Global Change, Regional Response: The New International Context of Development. New York: Cambridge University Press.

STIGLITZ, J. (2002) Globalization and its Discontents. New York: Norton.

STRANGE, S. (1994) States and Markets. London/New York: Pinter Publishers.

TAVARES, M. C. (1985), “A retomada da hegemonia norte-americana”. In TAVARES, M. C. \& FIORI, J. L., orgs. Poder e Dinheiro. Petrópolis: Ed. Vozes, Petrópolis.

TAVARES, M. C. and MELIN, E., (1997) "Pós-escrito 1997: A reafirmação da hegemonia norte-americana”. In TAVARES, M. C. \& FIORI, J. L. orgs. Poder e Dinheiro. Petrópolis: Ed. Vozes.

TORRES Fo, E. T. (1997) "A crise da economia japonesa nos anos 90 e a retomada da hegemonia americana”. In TAVARES, M. C. \& FIORI, J. L. orgs. Poder e Dinheiro. Petrópolis: Ed. Vozes.

TRIFFIN, R. (1972) O Sistema Monetário Internacional. São Paulo: Editora Expressão e Cultura.

UN/UNCTAD (2000) World Investment Report 2000: Cross-border Mergers and Acquisitions and Development. Switzerland: United Nations Publication.

UN/UNCTAD (2001) World Investment Report 2001: Promoting Linkages. Switzerland: United Nations Publication.

UN/UNCTAD (2002) Trade and Development Report, 2002. France: United Nations Publication. 